\title{
INCREASED SEED SURVIVAL AND SEEDLING EMERGENCE IN A POLYPLOID PLANT INVADER ${ }^{1}$
}

\author{
Min A. Hahn² ${ }^{2}$ Tabea Lanz, Dominique Fasel, and Heinz Müller-Schärer
}

Department of Biology, Ecology and Evolution, University of Fribourg, Chemin du Musée 10, 1700 Fribourg, Switzerland

- Premise of the study: Because seeds have essential functions in the life cycle of plants, even subtle changes in their characteristics may have important demographic consequences. In this study, we examined whether potential changes in seed characteristics as a result of polyploidy or postintroduction evolution may have contributed to the invasion of Centaurea stoebe (Asteraceae). This plant occurs as diploid and tetraploid cytotypes in its native range in Europe, whereas only tetraploids have been found and become invasive in North America. Specific comparisons among these three "geo-cytotypes" allow us to explore hypotheses of preadaptation resulting from polyploidy (European diploids vs. European tetraploids) and postintroduction evolution (European tetraploids vs. North American tetraploids).

- Methods: Using seeds collected from plants of each geo-cytotype grown in a common maternal environment, we compared seed mass, morphology (achene and pappus size), dispersal potential (falling velocity, seed roughness), survival, germination, and seedling emergence in a combination of laboratory, greenhouse and field experiments.

- Key results: We found increased seed mass in North American tetraploids compared with European tetraploids. Seed morphology and dispersal potential were largely similar in all geo-cytotypes. Seed survival under field conditions was higher in native and invasive tetraploids compared with diploids. Germination in the laboratory was similar among all geo-cytotypes, but seedling emergence under field conditions was higher in invasive tetraploids than in the other geo-cytotypes.

- Conclusions: Our findings suggest that a combination of preadaptation due to polyploidy (increased seed survival) and further postintroduction evolution in North American tetraploids (increased seed mass and seedling emergence) may have contributed to their invasion.

Key words: Asteraceae; Centaurea stoebe; dispersal; seedling establishment; invasive species; polyploidy; postintroduction evolution; seed ecology; seed viability; spotted knapweed.

Seeds represent a crucial stage in the life cycle of plants because they contribute to various essential functions such as dispersal, escape from unfavorable growing conditions, and recruitment of new seedlings (Harper et al., 1970). This might in particular be true for invasive plants, which are often introduced as seeds and whose success is found to be associated with good abilities to disperse, colonize new localities and persist (Pyšek and Richardson, 2007). As even small changes in the characteristics of seeds may affect almost every aspect of their ecology, seed characteristics generally remain highly conserved within a species (Harper et al., 1970). Many studies have compared seed characteristics among species (e.g., Grime et al., 1981); however, only a few have looked at variation within species (e.g., Buckley et al., 2003). This is surprising, since comparisons among native and invasive genotypes may elucidate important mechanisms underlying the invasion success of a species (van Kleunen et al., 2010). In particular, such comparisons may

${ }^{1}$ Manuscript received 12 October 2012; revision accepted 29 April 2013.

The authors thank O. Tackenberg for support in determining falling velocity and roughness of seeds; Y. Buckley and P. Mráz for comments on the experimental procedure; A. Hahn for help in graphical transformation of seed images; R. Zindel, W. Hahn, L. Buholzer, S. Müller, D. Crottet, J.-B. Haas, M. Stokvis, M. Henery, B. Hall, H. Benson, J. Bielanska, and S. Rossinelli for assistance during the field experiment and data collection; and the School of Agriculture in Grangeneuve, Switzerland for providing and maintaining the experimental site. H.M.S. acknowledges funding by the Swiss National Science Foundation (SNSF grant 31003A_125314, and through the National Centre of Competence in Research 'Plant Survival').

${ }^{2}$ Author for correspondence (e-mail: min.hahn@gmx.ch) allow exploring the relative importance of preadaptation vs. postintroduction evolutionary changes, which both could contribute to an invasion.

In recent years, polyploidy, i.e., whole genome multiplication, has increasingly been recognized as a potential beneficial attribute of successful plant invaders (Pandit et al., 2011; te Beest et al., 2012). Polyploids, and in particular allopolyploids resulting from interspecific hybridization, may strongly differ from their diploid ancestors in their genetics, morphology, physiology, and ultimately also ecology (Levin, 1983), which could predispose them to become invasive. Associated with polyploidy, we may also expect changes in the characteristics and ecology of seeds. Polyploid cells are generally found to be larger, which may translate into increased seed size (Bretagnolle et al., 1995; Levin, 2002) and seed mass (Beaulieu et al., 2007). This increase in turn may affect seedling vigor (Bretagnolle et al., 1995) or the ability of a seed to disperse. Differences among cytotypes may also be found in seed viability, germination, and seedling emergence (Bretagnolle et al., 1995) with important consequences for the accumulation of seeds in the soil seed bank, successful plant recruitment and plant demography in general. However, empirical studies on effects of polyploidy on the ecology of seeds are rare and show complex patterns. For example, Bretagnolle et al. (1995) found higher and more rapid germination in tetraploid compared to diploid Dactylis glomerata independent of seed mass, while heavier seeds of tetraploids produced larger seedlings. Moreover, in addition to potential preadaptation due to such differences that result from genome multiplication, changes among native and invasive genotypes may further elucidate the direction of selection in the invasive range. 
In this study, we explore the role of polyploidy in shaping seed characteristics in the invasive plant Centaurea stoebe L. (Asteraceae). In the native range in Europe, these plants occur as diploids (EU $2 x$ ) and tetraploids (EU 4x), whereas in the introduced range in North America so far only tetraploids (NA $4 x$ ) have been found (Treier et al., 2009). Here, we refer to these three cytotype $\times$ continent combinations as geo-cytotypes. Tetraploids are of allopolyploid origin involving the hybridization with an unknown second parental species (Mráz et al., 2012a) and differ from diploids in several morphological characters (Mráz et al., 2011). Different comparisons of the three geocytotypes of $C$. stoebe may provide evidence for either preadaptation due to polyploidy (EU $2 x$ vs. EU $4 x$ ) or for adaptive postintroduction evolutionary changes or genetic drift (EU $4 x$ vs. NA $4 x$ ) promoting the invasion in North America. A number of comparative studies on plant traits of this species have indeed suggested a combination of these processes (Broz et al., 2009; Treier et al., 2009; Henery et al., 2010). Moreover, a recent comprehensive study on the demography of the three geocytotypes in a common garden field experiment revealed no difference in growth rates between European diploids and tetraploids, but increased population growth rates in invasive tetraploids as compared to European tetraploids (Hahn et al., 2012a). Most interestingly, the increased population growth resulted mainly from increased seed production and juvenile establishment in North American tetraploids, which suggests that in par- ticular changes in seed characteristics may have played an important role for the invasion success of this species. However, more detailed knowledge on the role of potentially important seed characteristics of this species is lacking. In particular, it remains unknown which physiological and ecological processes (e.g., seed survival, germination, seedling emergence, and establishment) led to the observed increased juvenile establishment of North American tetraploids and whether other seed characteristics (e.g., dispersal traits) have been affected by these differences as well. A more general investigation on potential changes in seed characteristics due to polyploidy and postintroduction evolution may provide a more comprehensive view on this critical life-cycle stage and the associated success of this species.

Using seeds collected from plants grown in a common maternal environment, we studied genetically based differences in seed characteristics among the three geo-cytotypes. We determined seed mass, morphology (achene and pappus length and width), and dispersal potential (falling velocity, seed roughness) and explored seed survival in the soil seed bank under field conditions, seed viability and germination in the laboratory, and seedling emergence in greenhouse and field experiments. Specifically, we asked (1) whether native European diploids and tetraploids differ in these seed characteristics, which may contribute to the invasion success and thus may indicate preadaptation through polyploidy, and (2) whether native European and invasive North American tetraploids differ in these seed characteristics, which could indicate potential adaptive postintroduction evolutionary changes or genetic drift promoting the invasion in North America.

\section{MATERIALS AND METHODS}

Study species-Centaurea stoebe L. (syn. C. maculosa Lam., Asteraceae) is a short-lived herbaceous plant. In its native range in Europe, it occurs as two cytotypes mostly in monocytotypic populations (Treier et al., 2009; Mráz et al.,
2011). Diploids $(2 n=36)$ are monocarpic annuals or biennials, whereas tetraploids are polycarpic perennials (Müller, 1989; Broz et al., 2009) and differ in several morphological characters (Mráz et al., 2011). In North America, where this plant was introduced as a seed contaminant of alfalfa seeds in the late 19th century and has become one of the most aggressive rangeland weeds (Sheley et al., 1998), so far only tetraploids have been found (Treier et al., 2009). Molecular analyses have provided clear evidence for multiple introductions (Marrs et al., 2008) and a common allopolyploid origin of European and North American tetraploids (Mráz et al., 2012a). Centaurea stoebe is insect-pollinated, obligate outcrossing, and reproduces solely by seeds. Individual plants produce an average of 1000 seeds (Schirman, 1981). Achenes are approximately $3 \mathrm{~mm}$ long and bear a pappus of simple, 1 to $2 \mathrm{~mm}$ long bristles (Sheley et al., 1998). Potential dispersal vectors include animals (mammals, birds, and insects) as well as humans (Sheley et al., 1998; Pearson and Ortega, 2001; Jensen and Six, 2006). Dispersal by wind is expected to be noneffective in $C$. stoebe, but may contribute to different short-distance dispersal patterns between the cytotypes and influence the potential to invade natural communities. Seeds can remain viable in the soil for more than $8 \mathrm{yr}$ (Davis et al., 1993) and germinate in a wide range of environments (Sheley et al., 1998).

Origin of seeds-All seeds used in this study originated from plants grown under similar maternal environmental conditions from a common garden experiment aimed at comparing the demography of the three geo-cytotypes (for details see Hahn et al., 2012a). For this purpose, monocultures of the three geocytotypes of $C$. stoebe were grown in artificial populations replicated in $2 \times 2 \mathrm{~m}$ plots for $3 \mathrm{yr}$ in the native range (Grangeneuve, Switzerland, N 46 $46.533^{\prime}$, E $\left.7^{\circ} 6.867^{\prime}\right)$. These artificial populations were created by pooling seedlings raised from seeds collected in 3-4 carefully selected natural populations from each of three geographically as well as ecologically similar regions per continent (according to Treier et al., 2009; Hahn et al., 2012a; Appendix S1, see Supplemental Data with the online version of this article). We thus had a representative sample of 10-12 populations per geo-cytotype (120-124 initial maternal lines per geo-cytotype), which also reflects the conditions of a major part of the distributional range of $C$. stoebe. A total of 36 plots were established ( 3 geocytotypes $\times 3$ regions $\times 2$ herbivore treatments $\times 2$ blocks); however, here we considered only the 18 plots without the herbivore treatment. While the maternal geo-cytotype of the seeds originating from these plots was known, the paternal origin of the seeds was not controlled. However, natural pollination (based on immediate sequence of flower visits) was observed mainly among plants within a plot (M. Hahn, unpublished data).

Seed mass, morphology, and dispersal potential - In autumn 2008, we collected bulk samples of 50 seeds from a subset of 5-10 individuals from each of the 18 plots ( 900 seeds in total). The seeds were weighed and achene and pappus length and width (relative to the main longitudinal seed axis) were measured on digital pictures of the seeds using a microscope-integrated camera and NIS FreeWare version 2.10 and ImageJ version 1.41o. As a crude approximation of dispersal potential of the seeds by wind (anemochory; Tackenberg et al., 2003), we determined the falling velocities of these seeds (not equal to terminal velocity). We used a special apparatus (similar to Askew et al., 1997) consisting of a vertical tube equipped with light barriers at both ends, which measures the time a seed needs to fall $1 \mathrm{~m}$ in the laboratory of O. Tackenberg, University of Frankfurt am Main, Germany (same method also used by Hintze et al., 2013). Although seeds of $C$. stoebe are unlikely to be dispersed by wind, subtle differences may influence short-distance dispersal and local distribution patterns, which may affect the level of intraspecific competition and the potential to reach suitable microsites within invaded, native communities. As an approximate measure for seed dispersal potential by attachment to animals (epizoochory), we determined the seed roughness from a random subset of three plots per geo-cytotype $(28,29$, and 27 seeds of EU $2 x$, EU $4 x$, and NA $4 x$, respectively). The same images used for morphological measurements were transformed into black and white images. Using the program KS300 version 3.0 (Carl Zeiss, Jena, Germany), we divided the perimeter of the convex envelope around the seed by the perimeter of the seeds, including all appendages, to provide a measure of seed roughness (the smaller the ratio, the larger the seed roughness; Römermann et al., 2005). Seed roughness was analyzed by O. Tackenberg.

Seed survival, germination, and seedling emergence-In 2009, we collected bulk samples of seeds from approximately 20 individuals from each plot. To estimate survival of the seeds in the soil seed bank under natural conditions in the field (mean temperatures: $-1{ }^{\circ} \mathrm{C}$ in January, $17.6^{\circ} \mathrm{C}$ in July; mean annual 
precipitation: $1118 \mathrm{~mm})$, we buried four bags $(10 \times 10 \mathrm{~cm}, 0.5 \mathrm{~mm}$ nylon mesh, $5-10 \mathrm{~cm}$ deep) each containing 100 seeds (3600 seeds in total) in each of nine plots of the demography experiment ( 3 geo-cytotypes $\times 3$ regions) in November 2009. In May and October 2010, two bags per plot were harvested, and the seeds tested for viability using a crush test that considers liquid traces of a crushed seed between two filter papers as evidence for viability (Sawma and Mohler, 2002). This crush viability test was validated with a viability test that uses tetrazolium chloride to stain living tissue (Lakon, 1949). An additional 100 European tetraploid seeds were cut longitudinally into two halves, one of which was subjected to the crush test, while the other was incubated in a $1 \%(\mathrm{w} / \mathrm{v})$ 2,3,5-triphenyl tetrazolium chloride aqueous solution for $20 \mathrm{~h}$ at $30^{\circ} \mathrm{C}$ and subsequently visually examined for stained tissue.

Another subset of 200 seeds per plot (3600 seeds in total) of the bulk samples collected in 2009 were used to study seed viability and germination under optimal laboratory conditions. Half of the seeds per plot were cold stratified at $4^{\circ} \mathrm{C}$ from 22 December 2009 to 9 March 2010 to simulate winter conditions as a potential dormancy breaking treatment. The other half of the seeds were kept in the dark at room temperature $\left(\sim 23^{\circ} \mathrm{C}\right)$ as a control. To examine effects of seed mass on seed viability and germination (in invasive North American tetraploids only), we weighed a subset of 300 individual seeds (150 cold stratified, 150 controls). In April 2010, the seeds were placed on moist filter paper in petri dishes each containing 50 seeds from the same plot in a climate chamber $(16 \mathrm{~h}$ light at $23^{\circ} \mathrm{C} / 8 \mathrm{~h}$ dark at $\left.13^{\circ} \mathrm{C}\right)$. Germination was recorded daily until day 15 when most of the seeds were germinated. Nongerminated seeds were tested for viability using the crush test as described above.

Furthermore, we investigated seedling emergence under seminatural greenhouse conditions (ambient conditions; mean temperature: $20^{\circ} \mathrm{C}$, mean relative humidity: $48 \%$, mean light: $3284 \mathrm{lum} / \mathrm{m}^{2}$ ) at the University of Fribourg, Switzerland. The seeds previously used for morphological measurements were individually sown into $2 \times 2 \mathrm{~cm}$ cells in 150 cell seedling trays at a depth of approximately $5 \mathrm{~mm}$ in April 2009. To test for effects of nutrients on germination and seedling emergence, we filled half of the trays with sterilized, unfertilized turf substrate (TKS1, Floragard, Oldenburg, Germany) and the other half with a similar but fertilized substrate (TKS2, Floragard). Five seeds from each of the 18 plots were sown in 10 seedling trays ( 90 seeds per tray). Due to the loss of some seeds, in total 857 seeds were sown. Positions of the seeds from different plots were randomized in each tray, and the trays in the greenhouse were regularly rearranged and watered. Emergence of seedlings was assessed daily from day 6 after sowing until day 30 .

In addition to the greenhouse experiments, seedling emergence was investigated in a common garden experiment at the same location as the demography experiment. A total of 18 plots $(25 \times 25 \mathrm{~cm}, 50 \mathrm{~cm}$ apart $)$ were treated with glyphosate and ploughed prior to the experiment. In November 2009, in each of the 18 seedling plots ( 3 geo-cytotypes $\times 3$ regions $\times 2$ replicates), 100 seeds were sown (corresponding to the demographic plots). Plots were continuously weeded in fall and early spring to minimize interspecific competition. In May 2010 , the number of successfully emerged seedlings was recorded.

Statistical analyses - We performed separate analyses for the comparisons of European diploids with European tetraploids and European tetraploids with North American tetraploids. Differences in seed mass, achene and pappus length and width, and seed falling-velocity and roughness were tested using linear mixed models (LMMs) with geo-cytotype as fixed and plot and region as random effects. Data were log-transformed if necessary to satisfy test assumptions. A hierarchical variance partitioning analysis was performed to calculate individual and joint contributions of seed mass, achene length and width as well as pappus length and width to falling velocity using the function hier.part from the $\mathrm{R}$ package hier.part (Walsh and MacNally, 2008). A similar analysis was performed for seed roughness, but excluding seed mass as contributing variable.

The results from the crush and tetrazolium chloride tests for seed viability were compared using Pearson's $\chi^{2}$ test. Seed survival (alive vs. dead) under field conditions in buried bags was analyzed using generalized linear mixed models (GLMMs) with geo-cytotype as fixed effect and bag nested in plot and region as random effects. Seed viability (germinated or nongerminated viable vs. dead), germination percentage (germinated $v s$. nongerminated viable) and germination speed (days from beginning of experiment until germination) un der laboratory conditions were compared using generalized linear mixed models (GLMMs) with geo-cytotype, cold treatment and their interaction as fixed effects and plot and petri dish as random effects. Differences in the length of germination period among geo-cytotypes and treatments were tested with an $F$-test. Effects of seed mass on viability and germination were analyzed for the subset of NA $4 x$, using GLMMs with seed mass, cold treatment, and their interaction as fixed effects and petri dish as random effect.
Seedling emergence (yes/no; speed) in the greenhouse was analyzed using GLMMs with geo-cytotype, fertilizer treatment, and interaction as fixed effects and plot and region as random effects. To determine the effect of seed mass on seedling emergence, we also constructed all GLMMs including seed mass and all interactions in the fixed part of the models. Seedling emergence in the field (number of seedlings per plot) was analyzed using LMM and geo-cytotype as fixed and region as random effect.

LMMs and GLMMs were fitted using the function lmer in the R package lme4 (Bates and Maechler, 2009) with identity (for normally distributed data), $\log$ (for count data), or logit (for binomial data) link function. Significances of model terms were assessed using likelihood ratio tests (LRT) on maximum likelihood (ML) estimations. Parameter estimates were calculated using restricted maximum likelihood (REML) estimations. All analyses were performed using the statistical software R version 2.9.2 (R Development Core Team, 2009).

\section{RESULTS}

Seed mass, morphology, and dispersal potential—We found no significant differences in seed mass among European diploids and European tetraploids, but significantly higher seed mass in North American tetraploids compared with European tetraploids (Table 1). Achene length and width were similar among the three geo-cytotypes (Table 1). European diploids had significantly longer pappi than European tetraploids, but we found no difference in pappus length between European and North American tetraploids (Table 1). Also, pappus width was similar in all geo-cytotypes (Table 1). Falling velocity did not differ significantly among the three geo-cytotypes, although the hierarchical partitioning revealed that it was mainly determined by seed mass (78.3\% of total variance explained; Appendix S2, see online Supplemental Data). Seed roughness as approximation for the potential for epizoochory was similar in all three geo-cytotypes (Table 1). The main contribution to seed roughness came from pappus width $(81.8 \%$ of total variance explained; Appendix S2).

Seed survival, germination, and seedling emergence-The results from the crush and tetrazolium chloride viability tests did not significantly differ $\left(\chi^{2}=0.86, \mathrm{df}=1, P<0.36\right)$, i.e., they were largely consistent. All seeds considered dead in the crush test $(N=47)$ remained unstained in the tetrazolium test, and only seven of the seeds that were considered alive in the crush test did not respond to the tetrazolium staining, which may be an artifact due to difficulties of cutting the small seeds into halves of equal size. Seed survival in buried bags under field conditions was higher in European tetraploids compared to $\mathrm{Eu}-$ ropean diploids, but similar in European and North American tetraploids (Table 2A). Also, regardless of native or invasive status, tetraploids showed higher seed survival compared to diploids $\left(\chi^{2}=4.6, \mathrm{df}=1, P<0.033\right)$. In the laboratory, we found increased seed viability in European tetraploids compared with diploids, but no significant difference in seed viability among European and North American tetraploids (Table 2A). In addition, in North American tetraploids seed mass was positively associated with seed viability $\left(\chi^{2}=26.1, \mathrm{df}=1, P<\right.$ 0.001 ); however, only a few nonviable seeds were found. The cold stratification affected neither the viability (EU $2 x$ vs. EU $4 x: \chi^{2}=0.2, \mathrm{df}=1, P<0.7 ;$ EU $4 x$ vs. NA $4 x: \chi^{2}=1.3, \mathrm{df}=1$, $P<0.3$ ) nor the percentage germination of the seeds (EU $2 x$ vs. EU $4 x: \chi^{2}=1.7, \mathrm{df}=1, P<0.2 ;$ EU $4 x$ vs. NA $4 x: \chi^{2}=0.1$, $\mathrm{df}=1, P<0.8$ ). In general, most of the seeds of all geo-cytotypes readily germinated under laboratory conditions (Table 2B). Also germination speed in the laboratory (ranging from 
TABLE 1. Seed characteristics of the three geo-cytotypes of Centaurea stoebe with estimated means and significance tests based on LRT from linear mixed effects models.

\begin{tabular}{|c|c|c|c|c|c|c|c|c|c|c|c|c|c|c|}
\hline \multirow[b]{2}{*}{ Trait } & \multirow[b]{2}{*}{ Unit } & \multicolumn{3}{|c|}{ Sample size } & \multicolumn{5}{|c|}{ EU $2 x$ vs. EU $4 x$} & \multicolumn{5}{|c|}{ EU $4 x$ vs. NA $4 x$} \\
\hline & & EU $2 x$ & EU $4 x$ & $\overline{\mathrm{NA}} 4 x$ & Mean EU $2 x$ & Mean EU $4 x$ & $\chi^{2}$ & df & $P$ & Mean EU $4 x$ & Mean NA $4 x$ & $\chi^{2}$ & $\mathrm{df}$ & $P$ \\
\hline Seed mass & $\mathrm{mg}$ & 284 & 287 & 286 & 1.7 & 1.8 & 0.36 & 1 & 0.549 & 1.8 & 2.1 & 5.60 & 1 & 0.018 \\
\hline Achene length & $\mathrm{mm}$ & 300 & 300 & 300 & 2.8 & 2.8 & 0.01 & 1 & 0.917 & 2.8 & 2.9 & 1.59 & 1 & 0.207 \\
\hline Achene width & $\mathrm{mm}$ & 300 & 300 & 300 & 1.2 & 1.3 & 2.59 & 1 & 0.108 & 1.3 & 1.3 & 2.61 & 1 & 0.106 \\
\hline Pappus length & $\mathrm{mm}$ & 300 & 300 & 300 & 1.6 & 1.3 & 4.40 & 1 & 0.036 & 1.3 & 1.4 & 1.71 & 1 & 0.192 \\
\hline Pappus width & $\mathrm{mm}$ & 300 & 300 & 300 & 1.6 & 1.6 & 0.09 & 1 & 0.768 & 1.6 & 1.8 & 3.81 & 1 & 0.051 \\
\hline Falling velocity & ms-1 & 289 & 289 & 289 & 2.9 & 3.0 & 0.35 & 1 & 0.557 & 3.0 & 3.1 & 1.85 & 1 & 0.174 \\
\hline Seed roughness & Polygon to seed ratio & 28 & 29 & 27 & 0.3 & 0.3 & 0.56 & 1 & 0.453 & 0.3 & 0.3 & 3.21 & 1 & 0.073 \\
\hline
\end{tabular}

Notes: Sample size: number of seeds; EU $2 x$ : European diploids, EU $4 x$ : European tetraploids, NA $4 x$ : North American tetraploids. Boldface $P$ values indicate significant effects $(P<0.05)$.

1-10 d) did not differ among the geo-cytotypes (Table 2B) and was not affected by the cold stratification (EU $2 x$ vs. EU $4 x$ : $\chi^{2}=1.1, \mathrm{df}=1, P<0.4 ;$ EU $4 x$ vs. NA $4 x: \chi^{2}=0.2$, df $=1, P<$ $0.7)$. The variation in germination speed, however, was greater for European tetraploids than for the other geo-cytotypes, indicating a longer period for germination (Table 2B). The cold stratification significantly reduced variation in germination speed $\left(\operatorname{var}_{\text {control }}=2.37, \operatorname{var}_{\text {cold }}=1.10, P<0.001\right)$. The percentage of seedling emergence in the greenhouse was similar in all three geo-cytotypes (Table 2C), nor did seedling emergence speed differ significantly among the three geo-cytotypes (Table 2C). However, seeds in the fertilized soil emerged earlier (average day of emergence: fertilized $=7.9$, unfertilized $=9.6$; EU $2 x$ vs. EU $4 x: \chi^{2}=24.6$, $\mathrm{df}=1, P<0.001 ;$ EU $4 x$ vs. NA $4 x: \chi^{2}=15.9$, df $=1, P<$ 0.001 ), but with lower percentage of emergence (fertilized $=$ $46 \%$, unfertilized $=55 \%$; EU $2 x$ vs. EU $4 x: \chi^{2}=4.8, \mathrm{df}=1$, $P<0.03$; EU $4 x$ vs. NA $4 x: \chi^{2}=6.1$, df $=1, P<0.02$ ). Independent of differences among geo-cytotypes, seed mass was positively correlated with the probability of seedling emergence (EU $2 x$ vs. EU $4 x: \chi^{2}=93.2, \mathrm{df}=1, P<0.001$; EU $4 x$ vs. NA $4 x: \chi^{2}=81.4$, df $\left.=1, P<0.001\right)$. Under field conditions, seedling emergence significantly increased in North American tetraploids compared with European diploids and tetraploids (Fig. 1, Table 2C).

\section{DISCUSSION}

Seed characteristics are in general known to be relatively stable within a species (Harper et al., 1970) because they represent an important life-cycle stage and are strongly tied to fitness. Our study revealed interesting differences among the three geo-cytotypes, indicating that both polyploidy and potential postintroduction evolutionary changes may have affected seed characteristics. Given the relative importance of the seed stage in the life cycle of $C$. stoebe as previously shown in a common garden demography experiment (Hahn et al., 2012a), these differences may indeed have considerably contributed to the invasion success of tetraploids in North America.

Seed mass, morphology, and dispersal potential-Polyploidy is generally associated with an increase in the size of seeds from diploids to tetraploids (Levin, 1983; Bretagnolle et al., 1995; Levin, 2002; Beaulieu et al., 2007), but we did not find significant differences in achene dimensions among the cytotypes. However, we found an increase in seed mass between the European and North American tetraploids, which may indicate evolutionary changes in the introduced range as also reported for other invasive species (Buckley et al., 2003).

In line with the largely similar seed morphology, dispersal potential was similar in all three geo-cytotypes. Although seed

TABLE 2. (A) Seed survival, (B) germination, and (C) seedling emergence of the three geo-cytotypes of Centaurea stoebe in the laboratory, greenhouse, and field with estimated means and significance tests based on LRT from (generalized) linear mixed effects models and $F$ test comparisons (for germination time variation).

\begin{tabular}{|c|c|c|c|c|c|c|c|c|c|c|c|c|c|c|c|}
\hline \multirow[b]{2}{*}{ Trait } & \multirow[b]{2}{*}{ Unit } & \multirow[b]{2}{*}{ Environment } & \multicolumn{3}{|c|}{ Sample size } & \multicolumn{5}{|c|}{ EU $2 x$ vs. EU $4 x$} & \multicolumn{5}{|c|}{ EU $4 x$ vs. NA $4 x$} \\
\hline & & & EU $2 x$ & EU $4 x$ & $\overline{\text { NA } 4 x}$ & EU $2 x$ & EU $4 x$ & $\chi^{2}$ & $\mathrm{df}$ & $P$ & EU $4 x$ & NA $4 x$ & $\chi^{2}$ & df & $P$ \\
\hline \multicolumn{16}{|l|}{ A) Seed survival } \\
\hline Survival spring & $\%$ & Field & 600 & 600 & 600 & 77.8 & 91.7 & 7.16 & 1 & 0.007 & 91.5 & 83.8 & 3.67 & 1 & 0.055 \\
\hline Survival fall & $\%$ & Field & 300 & 200 & 100 & 27.2 & 71.7 & 2.82 & 1 & 0.093 & 71.4 & 82.3 & 0.32 & 1 & 0.574 \\
\hline Viability & $\%$ & Laboratory & 600 & 600 & 600 & 86.7 & 97.4 & 10.69 & 1 & 0.001 & 97.0 & 94.7 & 3.81 & 1 & 0.051 \\
\hline \multicolumn{16}{|l|}{ B) Germination } \\
\hline Germination percentage & $\%$ & Laboratory & 510 & 582 & 568 & 97.0 & 98.1 & 0.84 & 1 & 0.361 & 97.9 & 97.1 & 0.28 & 1 & 0.595 \\
\hline Germination speed (mean) & Days & Laboratory & 487 & 566 & 544 & 2.5 & 2.4 & 0.08 & 1 & 0.777 & 2.4 & 2.5 & 0.11 & 1 & 0.745 \\
\hline Germination speed (var) & Days & Laboratory & 487 & 566 & 544 & 1.0 & 2.3 & - & - & 0.000 & 2.3 & 1.8 & - & - & 0.005 \\
\hline \multicolumn{16}{|l|}{ C) Seedling emergence } \\
\hline Emergence percentage & $\%$ & Greenhouse & 284 & 287 & 286 & 44.8 & 46.4 & 0.02 & 1 & 0.886 & 46.5 & 59.6 & 3.12 & 1 & 0.077 \\
\hline Emergence speed (mean) & Days & Greenhouse & 133 & 131 & 164 & 9.1 & 8.9 & 0.52 & 1 & 0.471 & 8.9 & 8.5 & 0.45 & 1 & 0.501 \\
\hline Seedling emergence & Counts & Field & 6 & 6 & 6 & 17.3 & 23.0 & 3.39 & 1 & 0.066 & 23.0 & 27.5 & 4.35 & 1 & $\mathbf{0 . 0 3 7}$ \\
\hline
\end{tabular}

Notes: EU 2x: European diploids, EU 4x: European tetraploids, NA $4 x$ : North American tetraploids. Significant effects $(P<0.05)$ are given in boldface. 


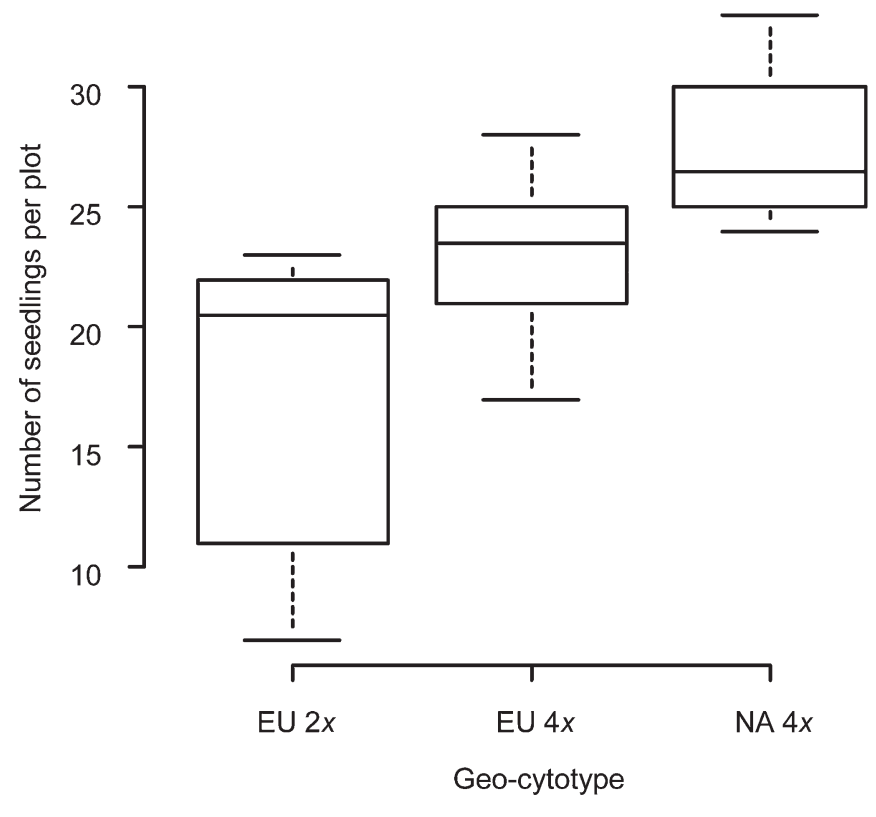

Fig. 1. Boxplots of numbers of emerged seedlings per plot of the three geo-cytotypes of Centaurea stoebe in the common garden experiment in spring 2010. EU $2 x$ : European diploids, EU $4 x$ : European tetraploids, NA $4 x$ : North American tetraploids. Sample sizes are $N=6$ plots ( 100 seeds per plot) per geo-cytotype. Statistics are given in Table 2C.

mass is one of the main determinants of dispersal potential by wind (Levin et al., 2003) and also directly affected the velocity of falling seeds in this study, we did not find significant differences in falling velocity among the geo-cytotypes. Thus, differences in local distribution patterns among cytotypes (Mráz et al., 2012b), which could affect the potential to reach suitable microsites and to invade native plant communities, may not be affected by falling velocity. Given the high falling velocities of the seeds of $C$. stoebe compared with other species in the family of Asteraceae (Andersen, 1992), wind dispersal as a long-distance dispersal vector in this species is very unlikely. Furthermore, our assessment of seed roughness as an approximation for the potential of dispersal through attachment to the fur or feathers of animals (Römermann et al., 2005) revealed no differences among seeds of the three geo-cytotypes. Thus, although seed mass in North American tetraploids was higher compared with the other geo-cytotypes, generally differences in the studied seed characteristics relevant for dispersal may play only a minor role for the invasion success of tetraploids. Nevertheless, secondary dispersal by ants may also be mediated by the presence of elaiosomes in seeds of C. stoebe (Jensen and Six, 2006). This possibility was not explicitly studied here, but it might affect local cytotype distribution patterns and invasion into native plant communities. In this context, a detailed examination of the causes of the increased seed mass (e.g., through increased elaiosome size) in invasive tetraploids may provide interesting insights.

Seed survival, germination, and seedling emergence-From seed maturation on the mother plant until successful establishment of a new seedling, a seed is exposed to various hazards. Seed survival under harsh conditions (e.g., during winter) and the correct timing of germination are important for subsequent successful seedling establishment. In correlation with seed mass, our findings showed increased seed viability in invasive tetraploid C. stoebe in the laboratory. Furthermore, a higher seed survival of tetraploid $C$. stoebe also became apparent under natural conditions in the field. This increased survival may promote the accumulation of soil seed banks, which might be important in particular for short-lived plants as a buffer against environmental stochasticity (Schirman, 1981; Hesse et al., 2007). The generally high fecundity of $C$. stoebe (Schirman, 1981) and the potential of seeds to persist in the soil for at least for $8 \mathrm{yr}$ (Davis et al., 1993) suggest a large potential for rapid accumulation of seeds in the soil. A recent study also reported higher lifetime fecundity in tetraploid $C$. stoebe than in diploids and in invasive North American tetraploids fecundity at first reproduction was increased compared to native tetraploids (Hahn and Müller-Schärer, 2013). These differences in fecundity may reinforce the observed patterns for individual seeds at the level of population dynamics. Buffering populations through repeated seedling recruitment from the soil seed bank might also be particularly important in the introduced range in North America, where drier and warmer climatic conditions (Broennimann et al., 2007) may increase seedling mortality. More generally, plant invaders may profit from soil seed banks by promoting successful establishment and local dominance and increasing the chance of secondary dispersal (Levin et al., 2003).

Because germination is an all-or-nothing event, the correct timing is crucial for the successful recruitment of a new seedling. Seeds may rest in a dormant state, in which they typically undergo a series of physical and physiological changes underlying complex regulatory mechanisms (Finch-Savage and LeubnerMetzger, 2006). In our experiment, we simulated winter conditions by cold stratification, which did not show significant effects on germination percentage and speed. But interestingly, the period of germination (variance in germination speed) declined in cold-stratified seeds, which may indicate that in some seeds germination was triggered by cold stratification. However, because seeds of $C$. stoebe can germinate either in fall or spring (Sheley et al., 1998), cold stratification might not be required to break dormancy, while other environmental cues such as light, temperature and humidity may be more important for the regulation of germination. Concordantly, Nolan and Upadhyaya (1988) described three types of dormant seeds in C. stoebe with light as the main regulating factor.

High germination rates may in general be advantageous, but the benefit of specific timing and speed of germination may strongly depend on the particular habitat conditions (Grime et al., 1981). In the laboratory, polyploidy had no effect on the germination percentage, but increased the variation in germination speed, thereby allowing both faster and slower germination in tetraploids compared with diploids. Seedling emergence under more natural conditions in the field was significantly increased in North American tetraploids compared with European diploids and tetraploids (Fig. 1). These differences in emergence among the geo-cytotypes in contrast to the similarities in germination suggest that the geo-cytotypes mainly differ in postgermination early seedling growth, which has been found in other invasive plants as well (Sharma and Dakshini, 1996; van Kleunen and Johnson, 2007; Perglova et al., 2009). Increased germination percentage and faster germination have also been previously reported in polyploids (e.g., Bretagnolle et al., 1995; Haouala et al., 2009). Moreover, seedling size is often found to be positively correlated with seed size and mass (Grime et al., 1981; Bretagnolle et al., 1995), presumably due to reserve effects (Westoby et al., 1996). Thus, competitively superior 
seedlings may explain the increased emergence rates of North American tetraploids observed in our experiment. Besides intrinsic differences, seeds of the geo-cytotypes may differ in their interactions with the extrinsic environment (e.g., through ecological tolerance), which may have led to the observed disparate seedling emergence. These results are well in line with the previously suggested evolutionary changes in North American tetraploids indicated by increased seedling recruitment in artificial populations (involving intraspecific competition of plants of different age), which may translate into increased population growth rates in North American tetraploids and contribute to their invasiveness (Hahn et al., 2012a).

Preadaptation and potential evolution in the invasion of $\mathrm{C}$. stoebe-Our findings suggest that the increased seed survival in tetraploids over that of the diploids, potentially mediated by polyploidy, may preadapt and facilitate their invasion into North America. This result is consistent with the increasingly recognized importance of polyploidy in invasions in general (te Beest et al., 2012). However, in addition to the multitude of effects of genome doubling per se (Levin, 1983), tetraploid $C$. stoebe might differ in several characteristics from diploids due to their allopolyploid origin (Mráz et al., 2012a).

In line with previous studies (Henery et al., 2010; Hahn et al., 2012a), increased seed mass and seedling emergence in invasive tetraploids compared with native tetraploids are consistent - with the hypothesis of adaptive postintroduction evolutionary changes, or alternatively genetic drift promoting the invasion in North America. Adaptive evolutionary changes could result D) from a shift in resource allocation from defense toward reproduction following the initial release from specialist herbivores $j$ in the introduced range, as indicated by a decline in transcription of defense related proteins in North American tetraploids (Broz et al., 2009). Similarly, an increase in seed size has been reported from native to invasive Cytisus scoparius (Buckley et al., 2003). However, despite evidence for multiple introductions of C. stoebe to North America (Marrs et al., 2008), which may also have contributed to adaptive evolution through hybridization of various ecotypes, we cannot fully exclude the possibility that these differences are due to genetic drift rather than adaptive evolution and ongoing extensive molecular marker studies are necessary to distinguish between these hypotheses.

Because different seed characteristics are required for different functions, seeds may represent complex adaptive compromises (Harper et al., 1970). A trade-off commonly reported exists between traits facilitating dispersal (e.g., small seed size and low seed mass) and traits, favoring germination and seedling establishment (e.g., larger and heavier seeds with more reserves) (Westoby et al., 1996). Our results suggest that selection in the introduced range of $C$. stoebe might have favored heavier seeds, conferring enhanced viability and seedling emergence, rather than seeds with increased dispersal abilities (unless increased seed mass is related to elaiosome size and secondary dispersal by ants, discussed earlier). Traits favoring successful seedling emergence and establishment might be disproportionally more important because they ultimately determine effective dispersal. Therefore, selection on these traits may be much stronger, whereas optimization of dispersal traits might be less stringent.

A major strength of this study is the comparison of seeds from plants grown in a common environment, allowing us to specifically examine genetically based differences among the geo-cytotypes. We acknowledge that in natural situations divergent habitat conditions could result in different outcomes. Since the seeds used in this study originated from plants grown under conditions in the native range, they may not be representative of those produced in natural populations (e.g. seeds from the introduced range in North America). In case of adaptation to the conditions in North America, differences in seed traits among native and invasive geo-cytotypes may presumably be underestimated. Moreover, because the paternal origin of the seeds was not controlled in this experiment, potential crossings between European and North American tetraploids, although assumed to be low, may likewise result in underestimated differences among geo-cytotypes. In contrast, due to a strong prezygotic barrier between diploid and tetraploid C. stoebe (Mráz et al., 2012b), cross-pollination between diploids and tetraploids is expected to result mostly in undeveloped seeds, which were not considered in this study.

In conclusion, besides other factors that may have contributed to the invasion success of tetraploid $C$. stoebe, as e.g., changes in life cycles (Henery et al., 2010) or phenotypic plasticity (Hahn et al., 2012b), this study indicates that polyploidy as well as postintroduction evolution may have affected seed characteristics (i.e., increased seed survival in tetraploids and increased seed mass and seedling emergence in North American tetraploids, respectively), which in turn may have contributed to the invasiveness of tetraploid $C$. stoebe in North America. More generally, our findings highlight that selective forces acting during invasions may affect even highly conserved seed characteristics and underlines the potential importance of subtle differences in the ecology of seeds for a plant's fitness.

\section{LITERATURE CITED}

Andersen, M. C. 1992. An analysis of variability in seed settling velocities of several wind-dispersed Asteraceae. American Journal of Botany 79: 1087-1091.

Askew, A. P., D. Corker, D. J. Hodkinson, and K. Thompson. 1997. A new apparatus to measure the rate of fall of seeds. Functional Ecology 11: $121-125$.

Bates, D., AND M. MAechler. 2009. lme4: Linear mixed-effects models using S4 classes. R package version 0.999375-32.

Beaulieu, J. M., A. T. Moles, I. J. Leitch, M. D. Bennett, J. B. Dickie, And C. A. Knight. 2007. Correlated evolution of genome size and seed mass. New Phytologist 173: 422-437.

Bretagnolle, F., J. D. Thompson, and R. Lumaret. 1995. The influence of seed size variation on seed germination and seedling vigor in diploid and tetraploid Dactylis glomerata L. Annals of Botany 76: 607-615.

Broennimann, O., U. A. Treier, H. Müller-Schärer, W. Thuiller, A. T. Peterson, and A. Guisan. 2007. Evidence of climatic niche shift during biological invasion. Ecology Letters 10: 701-709.

Broz, A. K., D. K. Manter, G. Bowman, H. Müller-Schärer, and J. M. Vivanco. 2009. Plant origin and ploidy influence gene expression and life cycle characteristics in an invasive weed. BMC Plant Biology 9: 33 .

Buckley, Y. M., P. Downey, S. V. Fowler, R. Hill, J. Memmot, H. Norambuena, M. Pitcairn, et Al. 2003. Are invasives bigger? A global study of seed size variation in two invasive shrubs. Ecology 84: 1434-1440.

Davis, E. S., P. K. Fay, T. K. Chicoine, and C. A. Lacey. 1993. Persistence of spotted knapweed (Centaurea maculosa) seed in soil. Weed Science 41: 57-61.

Finch-Savage, W. E., And G. Leubner-Metzger. 2006. Seed dormancy and the control of germination. New Phytologist 171: 501-523.

Grime, J. P., G. Mason, A. V. Curtis, J. Rodman, S. R. Band, M. A. G. Mowforth, A. M. Neal, Et AL. 1981. A comparative study of 
germination characteristics in a local flora. Journal of Ecology 69: 1017-1059.

Hahn, M. A., AND H. Müller-SchÄrer. 2013. Cytotype differences modulate eco-geographical differentiation in the widespread plant Centaurea stoebe. Ecology 94: 1005-1014.

Hahn, M. A., Y. M. Buckley, AND H. Müller-SchäRer. 2012a. Increased population growth rate in invasive polyploid Centaurea stoebe in a common garden. Ecology Letters 15: 947-954.

Hahn, M. A., M. van Kleunen, And H. Müller-Schärer. 2012b. Increased phenotypic plasticity to climate may have boosted the invasion success of polyploid Centaurea stoebe. PLoS ONE 7: e50284.

Haouala, R., S. Ouerghemmi, A. Tarchoune, and N. Boughanmi. 2009. Improvement of Trigonella maritima Delilee $\times$ Poir. germination by polyploidization. Pakistan Journal of Botany 41: 3001-3008.

Harper, J. L., P. H. Lovell, And K. G. Moore. 1970. The shapes and sizes of seeds. Annual Review of Ecology and Systematics 1: 327-356.

Henery, M. L., G. Bowman, P. Mráz, U. A. Treier, E. Gex-Fabry, U. SCHAFFNER, AND H. MÜLLER-SChärER. 2010. Evidence for a combination of pre-adapted traits and rapid adaptive change in the invasive plant Centaurea stoebe. Journal of Ecology 98: 800-813.

Hesse, E., M. Rees, And H. Müller-Schärer. 2007. Seed bank persistence of clonal weeds in contrasting habitats: Implications for control. Plant Ecology 190: 233-243.

Hintze, C., F. Heydel, C. Hoppe, S. Cunze, A. König, and O. Tackenberg. 2013. D ${ }^{3}$ : The Dispersal and Diaspore Database-Baseline data and statistics on seed dispersal. Perspectives in Plant Ecology, Evolution and Systematics 15:180-192.

Jensen, J. M., And D. L. Six. 2006. Myrmecochory of the exotic plant, Centaurea maculosa: A potential mechanism enhancing invasiveness. Environmental Entomology 35: 326-331.

LAKON, G. 1949. The topographical tetrazolium method for determining the germinating capacity of seeds. Plant Physiology 24: 389-394.

Levin, D. A. 1983. Polyploidy and novelty in flowering plants. American Naturalist 122: 1-25.

LEvin, D. A. 2002. The role of chromosomal change in plant evolution. Oxford University Press, New York, New York, USA.

Levin, S. A., H. C. Muller-Landau, R. Nathan, and J. Chave. 2003. The ecology and evolution of seed dispersal: A theoretical perspective. Annual Review of Ecology, Evolution and Systematics 34: 575-604.

Marrs, R. A., R. Sforza, and R. A. Hufbauer. 2008. Evidence for multiple introductions of Centaurea stoebe micranthos (spotted knapweed, Asteraceae) to North America. Molecular Ecology 17: 4197-4208.

Mráz, P., R. Bourchier, U. A. Treier, U. Schaffner, and H. MüllerSCHÄRER. 2011. Polyploidy in phenotypic zpace and invasion context: A morphometric study of Centaurea stoebe s.1. International Journal of Plant Sciences 172: 386-402.

Mráz, P., N. Garcia-Jacas, E. Gex-Fabry, A. Susanna, L. Barres, and H. MÜLLER-SCHÄRER. 2012a. Allopolyploid origin of highly invasive Centaurea stoebe s.1. (Asteraceae). Molecular Phylogenetics and Evolution 62: 612-623.

Mráz, P., S. Španiel, A. Keller, G. Bowmann, A. Farkas, B. Šingliarová, R. P. Rohr, ET AL. 2012b. Anthropogenic disturbance as a driver of microspatial and microhabitat segregation of cytotypes of Centaurea stoebe and cytotype interactions in secondary contact zones. Annals of Botany 110: 615-627.

MüLLER, H. 1989. Growth pattern of diploid and tetraploid spotted knapweed, Centaurea maculosa Lam. (Compositae), and effects of the root-mining moth Agapeta zoegana (L.) (Lep: Cochylidae). Weed Research 29: 103-111.

Nolan, D. G., And M. K. Upadhyaya. 1988. Primary seed dormancy in diffuse and spotted knapweed. Canadian Journal of Plant Science 68: 775-783.

Pandit, M. K., M. J. O. Pocock, And W. E. Kunin. 2011. Ploidy influences rarity and invasiveness in plants. Journal of Ecology 99: 1108-1115.

Pearson, D. E., And Y. K. OrTEga. 2001. Evidence of an indirect dispersal pathway for spotted knapweed, Centaurea maculosa, seeds, via deer mice, Peromyscus maniculatus, and great horned owls, Bubo virginianus. Canadian Field Naturalist 115: 354.

Perglova, I., J. Pergl, H. Skalova, L. Moravcova, V. Jarosik, and P. PySEK. 2009. Differences in germination and seedling establishment of alien and native Impatiens species. Preslia 81: 357-375.

PyšEK, P., AND D. M. Richardson. 2007. Traits associated with invasiveness in alien plants: where do we stand? In W. Nentwig [ed.], Biological invasions, 97-126. Springer, Berlin, Germany.

R Development Core Team. 2009. R: A language and environment for statistical computing. R Foundation for Statistical Computing, Vienna, Austria.

Römermann, C., O. Tackenberg, and P. Poschlod. 2005. How to predict attachment potential of seeds to sheep and cattle coat from simple morphological seed traits. Oikos 110: 219-230.

Sawma, J. T., AND C. L. Mohler. 2002. Evaluating seed viability by an unimbibed seed crush test in comparison with the tetrazolium test. Weed Technology 16: 781-786.

SchIRMAN, R. 1981. Seed production and spring seedling establishment of diffuse and spotted knapweed. Journal of Range Management 34: 45-47.

Sharma, R., AND K. M. M. DaKshini. 1996. Ecological implications of seed characteristics of the native Prosopis cineraria and the alien $P$. juliflora. Vegetatio 124: 101-105.

Sheley, R. L., J. S. Jacobs, And M. F. CARPInelli. 1998. Distribution, biology, and management of diffuse knapweed (Centaurea diffusa) and spotted knapweed (Centaurea maculosa). Weed Technology 12: 353-362.

Tackenberg, O., P. Poschlod, And S. Bonn. 2003. Assessment of wind dispersal potential in plant species. Ecological Monographs 73: 191-205.

te Beest, M., J. J. Le Roux, D. M. Richardson, A. K. Brysting, J. Suda, M. Kubesova, And P. PyšEk. 2012. The more the better? The role of polyploidy in facilitating plant invasions. Annals of Botany 109: 19-45.

Treier, U. A., O. Broennimann, S. Normand, A. Guisan, U. Schaffner, T. Steinger, AND H. Müller-SchÄrer. 2009. Shift in cytotype frequency and niche space in the invasive plant Centaurea maculosa. Ecology 90: 1366-1377.

van Kleunen, M., W. Dawson, D. Schlaepfer, J. M. Jeschke, and M. FISCHER. 2010. Are invaders different? A conceptual framework of comparative approaches for assessing determinants of invasiveness. Ecology Letters 13: 947-958.

van Kleunen, M., And S. D. Johnson. 2007. South African Iridaceae with rapid and profuse seedling emergence are more likely to become naturalized in other regions. Journal of Ecology 95: 674-681.

WALSh, C., AND R. MACNALLY. 2008. hier.part: Hierarchical partitioning. $\mathrm{R}$ package version 1.0-3.

Westoby, M., M. Leishman, And J. Lord. 1996. Comparative ecology of seed size and dispersal. Philosophical Transactions of the Royal Society of London, B, Biological Sciences 351: 1309-1317. 